\section{Terapia Dinámica Interpersonal Breve, Guía Clínica}

\author{
Brief Dynamic Interpersonal Therapy: A \\ Clinician's Guide
}

Alessandra Lemma, Mary Target y Peter Fonagy

Traducción al español realizada por:

Grupo Chileno de Psicoterapia Dinámica

Interpersonal Breve para Depresión y Ansiedad, coordinado por Dr. Marcelo Girardi

\section{Autor de la reseña:}

Guillermo de la Parra ${ }^{\mathrm{a}}$

\section{Contexto histórico}

Dentro de la corriente psicoanalítica las terapias psicodinámicas breves aparecen, después de la segunda guerra, como un esfuerzo para responder a las demandas de psicoterapia a nivel de la salud mental pública. Cuando decimos breves estamos comparando con los psicoanálisis o las terapias sin fecha de término de los años 50, 60 y 70 del siglo pasado. Estas terapias, para ser breves debían focalizar. Desde un punto de vista psicodinámico, el foco es aquello que subyace a los síntomas, al motivo de consulta, lo que explica psicodinámicamente las dificultades del paciente, y cuyo tratamiento, tratamiento del foco, llevaría a la mejoría sintomática. El libro que se reseña aquí, define la formulación psicodinámica (foco), como aquella "que conecta la teoría con la práctica; garantiza que la terapia esté diseñada de acuerdo a las necesidades de cada paciente y ofrece un foco para el trabajo, contribuyendo así a determinar la dirección y los objetivos del tratamiento... es decir, una formulación psicodinámica se propone identificar los factores externos e internos que han contribuido al problema y/o lo están manteniendo".

Existen dos tradiciones en las terapias breves $^{\mathrm{b}}$ : las primeras, que siguen una tradición pulsional-estructural, freudiana, basada en la

aDepartamento de Psiquiatría, Escuela de Medicina, Pontificia Universidad Católica de Chile.

${ }^{\mathrm{b}}$ Messer \& Warren, 1995. psicología del yo, donde el foco es un conflicto subyacente (por ejemplo síntoma/defensa-angustia-pulsión/“sentimiento soterrado") y cuyos representantes más típicos son Davanloo, Sifneos y en parte Malan y las segundas, las terapias que siguen la teoría de las relaciones objetales con orígenes en Klein, Fairbain, Winnicott, Balint, Sullivan, donde el foco será un patrón relacional disfuncional cuyos representantes son entre otros Luborsky con el CCRT, Horowitz, Weiss y Strupp con el TLDP.

La Terapia Dinámica Interpersonal Breve (TDI), que describe este libro se inscribe en esa última tradición y plantea como foco un "patrón interpersonal inconsciente, dominante y recurrente, el Foco Afectivo Interpersonal (FAI)".

Estas dos tradiciones en terapias focales dejan fuera lo que de Johnge (1993) llamó “Teoría Post Clásica”, donde el origen de las dificultades, síntomas, del paciente son una manifestación directa de una falla básica, de déficits en el funcionamiento de la estructura de personalidad (lo que llama De Johnge funcionamiento arcaico de la mente) y donde no cabe buscar un conflicto subyacente a los síntomas como ocurre en lo que plantea él como teoría clásica (funcionamiento neurótico de la mente) y que se corresponde con los modelos presentados recién. Si bien otras terapias focales se hacen cargo de este funcionamiento arcaico de la mente (como el Diagnóstico Psicodinámico Operacionalizado, OPD), en el caso de la Terapia Interpersonal Breve sí asumen, cumpliéndose ciertas condiciones que se comentan más adelante, pacientes con "dificultades moderadas", donde la depresión puede estar teñida por manifestaciones secundarias a la estructura de personalidad.

\section{Contexto competencias y realidad chilena}

Se ha visto empíricamente ${ }^{c}$ que las psicoterapias en instituciones son breves de por sí: el paciente las deja ya sea porque no encuentran lo que necesitan, es decir el terapeuta no sabe, no tiene las compe-

cde la Parra y cols. 2017, de la Parra y cols. 2018. 
tencias necesarias para adaptarse a los requerimientos del paciente en ese contexto institucional o porque dada la carga del contexto socioeconómico que enfrentan los pacientes, los hace dejar las terapias una vez que están "suficientemente bien", con el riesgo de recurrencias.

Es ahí, en el contexto institucional, donde los psicoterapeutas psicodinámicos enfrentan el desafío de salir del modelo de consulta, que muchos psicólogos-psicoterapeutas han aprendido en sus escuelas e institutos y que corresponde a un tipo de atención que está al alcance de solo una minoría de nuestra población, y que se caracteriza por terapias sin fecha de término, donde el terapeuta descansa en la iniciativa del paciente de traer "material" y financiar indefinidamente sus tratamientos.

La Guía Clínica Terapia Dinámica Interpersonal (TDI) nace originalmente de la necesidad de entregar competencias a terapeutas dinámicos a nivel de la salud mental pública en Reino Unido, por lo que viene a llenar un vacío en cuanto a las competencias que los psicoterapeutas dinámicos requieren en su trabajo institucional

Algunas de las competencias que puede aprender, mediante el manual que aquí se reseña, los psicoterapeutas dinámicos y que no necesariamente aprendieron en el pregrado o los respectivos institutos son por ejemplo:

- Capacidad de motivar y comprometer al paciente en el trabajo terapéutico: lo que implica discutir explícitamente los objetivos terapéuticos con éste.

- Capacidad de evaluar la posible pertinencia de la indicación de este enfoque psicodinámico interpersonal.

- Capacidad de captar las temáticas interpersonales recurrentes.

- Capacidad de trabajar con la realidad interna y externa del paciente.

- Capacidad de establecer un foco psicodinámico y luego mantenerlo y seguirlo a través del proceso.

- Como novedad también para el terapeuta psicodinámico está la monitorización del proceso a través de instrumentos que se responden sesión a sesión y su uso clínico con el paciente.
La Guía Clínica corresponde, entonces, a un protocolo que pretende ayudar a "los terapeutas de formación psicodinámica a trabajar en torno a un foco específico relevante para las dificultades habituales de los pacientes con depresión y/o ansiedad", donde destacaría que se trata de un protocolo no solo teóricamente informado sino que empíricamente informado, de tal manera que se apoya fuertemente en la teoría de las relaciones objetales, pero también en los hallazgos de la investigación empírica en apego y sus consecuencias cerebrales y relacionales y en la investigación en mentalización. Como lo plantean ellos, se trataría de: "un protocolo de práctica psicodinámica que promueve una traducción rápida desde el insight psicológico a un cambio a nivel de los síntomas y que, al mismo tiempo, aprovecha al máximo el progreso científico para comprender los principios generales del cambio conductual e incorporarlos en una terapia genérica y pragmática”.

La Guía Clínica parte de la premisa básica de que "los síntomas presentes en los trastornos del ánimo son respuestas a dificultades interpersonales y/o amenazas percibidas a las relaciones de apego (pérdida/separación) y, por lo tanto, percibidas también como amenazas al self, es decir, una desorganización transitoria subyacente del sistema de apego".

Algunos de los aspectos especialmente relevantes de esta obra que fluye a través de 10 capítulos más un capítulo de Preguntas Frecuentes, se resumen (y citan) a continuación bajo los acápites: indicación, foco, fases del tratamiento y alcances técnicos.

\section{Indicación, factores de inclusión y exclusión}

- Factores de inclusión a evaluar en las 4 primeras sesiones respecto a la indicación de TDI:

- Que el paciente tenga una cierta red de apoyo.

- Que se den las condiciones de contexto (pago, distancia, trabajo) para que el paciente acuda a las sesiones y se mantenga por 16 semanas. 
- Interés del paciente por trabajar temas interpersonales y afectivos: ya que la TDI se centra inequívocamente en el funcionamiento interpersonal del paciente en su vida actual, en la interacción terapéutica, y en su experiencia emocional.

- Capacidad del paciente de no solo hacer insight sino de aceptar el desafío de "probar nuevas formas de llevar sus relaciones".

- Capacidad del paciente de reflexionar sobre la relación terapéutica.

- Capacidad del paciente de contactarse con sentimientos y/o temas interpersonales dolorosos.

- Factores de exclusión

- "Pacientes que no tengan ningún interés y/o capacidad de reflexionar sobre algunas de sus propias contribuciones a la perpetuación de dinámicas relacionales problemáticas”.

- Trastornos de personalidad, aunque sí pacientes con "dificultades moderadas", como decíamos más arriba.

\section{Foco, o reformulación de los síntomas como una temática relacional}

Las 16 sesiones a razón de frecuencia semanal se estructuran "en torno a la formulación y elaboración de un patrón afectivo interpersonal recurrente y problemático que se convierte en el foco del trabajo, es decir, el FAI (Foco Afectivo Interpersonal)"

El foco se basa en la conceptualización de Kernberg "en que se configura el conflicto inconsciente como el resultado de un choque entre representaciones específicas del self y el otro del cual se derivan un patrón interpersonal recurrente y expectativas respecto a los demás".

En la práctica la conversación se centra en cuatro elementos :

1. Foco en la exploración de las dificultades actuales.

2. Foco en el afecto respecto a figuras de apego significativas en el presente, lo que implica.

a.Ayudar al pte a reconocer los sentimientos como propios.
b.Ayudar al paciente a diferenciar sentimientos de acciones.

c. Facilitar la conversación sobre la conexión entre sentimientos y acciones.

3. Foco en la relación terapéutica.

4. Foco en la mente del paciente: enfocándose consistentemente en sus estados mentales conscientes e inconscientes (p. 84).

\section{Las 16 sesiones y sus fases: la terapia se divide en tres fases}

Fase inicial (4 sesiones): En esta se establece el FAI a través de los episodios relacionales que refiere el paciente en relaciones presentes y del pasado y a través de la escenificación transferencial. El objetivo fundamental en esta etapa es "ayudar al paciente a pasar gradualmente de una posición en la que busca ayuda y alivio para sus síntomas a una posición en la que está interesado por el significado, por lo que está sucediendo en su mente y en sus relaciones".

Fase intermedia (8 sesiones): Aquí el terapeuta debe mantenerse firme ayudando al paciente a pensar en cómo contribuye ese patrón relacional a mantener el problema y/o síntoma(s) (p. 79).

Fase final (4 sesiones): En que junto con la exploración de la experiencia de término, el terapeuta usa las últimas sesiones como oportunidad para llevar al paciente a revisar el trabajo en torno al FAI (lo que incluye escribirle una "carta de despedida" con un resumen de dicho foco de trabajo)

\section{Algunos alcances técnicos}

Las técnicas expresivas y de apoyo incluyen la exploración focalizada de la relación transferencial y no son tan diferentes a las demás terapias psicodinámicas, la guía clínica estimula además explícitamente la mentalización a través de lo que llama preguntas útiles e intervenciones mentalizadoras, por parte de un terapeuta quien destaca por una "actitud inquisitiva o de "no saber", poniendo 
de relieve una actitud de curiosidad e indagación explícita, reflejando la idea de que los estados mentales son opacos y que el terapeuta no puede saber lo que está en la mente del paciente mejor que él mismo".

Finalmente, se trata de una obra muy lograda, así como su traducción, que resulta de lectura fácil y amena. El hecho de ofrecer una terapia breve susceptible de ser enseñada a terapeutas psicodinámicos que trabajan en instituciones, representa un importante aporte a la Salud Mental de nuestro país. Otros modelos de terapia breve relacional como el TLDP de Strupp y en parte el CCRT de Luborsky han caído en el desuso en su aplicación clínica, pero el hecho que la Guía Clínica TDI vaya acompañada de un curso que ofrecen los mismos autores de la traducción, donde además incluyen aspectos estructurales de la personalidad a través del OPD, le augura un promisorio presente y futuro. 